\title{
APLICAÇÃO DO MÉTODO DE ANÁLISE E SOLUÇÃO DE PROBLEMA: UM ESTUDO DE CASO EM UMA PANIFICAÇÃO
}

\author{
Kíssila da Conceição Ribeiro \\ Doutoranda em Planejamento Regional e Gestão de Cidades / Instituto Federal de Educação, Ciência e \\ Tecnologia Fluminense \\ kribeiro@iff.edu.br
}

Denise Cristina de Oliveira Nascimento

Doutora em Engenharia e Ciência dos Materiais/Universidade Federal Fluminense -UFF denise_cristin@yahoo.com.br

\section{Ricardo Luiz Manhães Sampaio Júnior}

Tecnólogo em Informática/Instituto Federal de Educação, Ciência e Tecnologia Fluminense rsampaio@iff.edu.br

\section{Eduardo Shimoda.}

Doutor em Ciência Animal/Universidade Estadual do Norte Fluminense Darcy Ribeiro - UENF prof_shimoda@yahoo.com.br

\section{RESUMO}

As empresas têm um ciclo de vida, porém sua duração pode variar de acordo como esta é conduzida. As dificuldades podem ser decorrentes de questões financeiras, econômicas, operacionais, entre outros, para isso as empresas devem procurar soluções para enfrentar estes desafios. Considerando a importância do setor de Panificação, o presente artigo objetiva a realização de estudo utilizando o Método de Análise de Solução de Problemas (MASP) em uma empresa de panificação situada em Campos dos Goytacazes-RJ, que vem tentando melhorar o seu cenário. Foi feito levantamento financeiro, observações "in loco" e aplicação de questionários aos funcionários e clientes, os dados foram tratados com os métodos estatísticos sendo estes a Satisfação Simples, GAP e abordagem multiplicativa. O apontamento dos métodos estatísticos e o brainstorming facilitaram na elaboração do diagrama de causa e efeito. Os resultados mostraram que a qualificação, motivação, absenteísmo, múltipla função, uniforme e aparência, quantidade de funcionário na área de venda, variedades dos produtos congelados de fabricação própria, falta de promoção, porção grande, climatização, planejamento da quantidade de produto produzido, falta de atenção, falta de cartão de crédito e fofoca são os itens que estão interferindo na vida financeira da empresa, sendo então proposto um plano de ação através do $5 \mathrm{~W} 1 \mathrm{H}$.

Palavras-chave: Qualidade; Panificação; Solução de problemas; MASP.

\begin{abstract}
Companies have a life cycle but the length of it may vary depending on how it is conducted. The difficulties may be caused by financial, economic, operational issues, among others things. Because of this, the companies should seek solutions to address these challenges. Considering the importance of the Bakery sector, the present article aims to carry out the study using the Troubleshooting Analysis Method (MASP) of a bakery located in the city of Campos dos Goytacazes-RJ, which has been trying to improve its scenario.
\end{abstract}

Persp. online: hum. \& sociais aplicada., Campos dos Goytacazes, 18 (7), 01-17, 2017

seer.perspectivasonline.com.br 
A financial survey and observations to the site were done, along with questionnaires to employees and customers, the data were processed with statistical methods and these the simple satisfaction, GAP and multiplicative approach. The applications of the statistical methods and brainstorm have facilitated the development of the cause and effect diagram. The results showed that the qualification, motivation, absenteeism, multiple functions, uniform and appearance, number of staff in the sales area, varieties of frozen products of its own production, lack of promotion, large portion, climate control, planning the amount of products produced, lack of attention, lack of credit card and gossip are all items that are interfering in the financial life of the company. With these types of results, an action plan of $5 \mathrm{~W} 1 \mathrm{H}$ has been proposed.

Keywords: Quality; Bakery; Troubleshooting; MASP.

\section{INTRODUÇÃO}

A globalização impõe as empresas a repensar no seu negócio, pois as relações mudaram, inovações tecnológicas surgiram, as distâncias tornaram insignificantes e os consumidores mais exigentes.

O atual cenário institui a qualidade como requisito básico, deixando de ser algo novo. Pinto e Gomes (2010) afirmam que a qualidade não é mais uma vantagem estratégica, ela está inserida no ambiente competitivo, sendo uma questão de sobrevivência nos dias de hoje.

E o ramo da panificação não é diferente, para conseguir conquistar os clientes as empresas estão tendo que inovar, aumentar o mix de produtos e consequentemente manter e superar a qualidade adquirida.

O cliente de hoje não procura somente o menor preço, ele quer ficar satisfeito com o produto ou serviço adquirido. Campos (2004) afirma que a qualidade de um produto ou serviço deve atender perfeitamente o cliente, de forma confiável, acessível, segura e no tempo certo às necessidades do cliente.

A qualidade para ser atingida decorre de uma busca e melhoria contínua. Com isso as empresas buscam métodos, instrumentos e ferramentas que possam proporcionar o alcance da qualidade e torna-las mais competitivas.

Com isso, decisões equivocadas podem resultar na falência de uma empresa. O principal objetivo deste estudo é verificar o que está ocasionando a redução do faturamento em uma empresa de panificação, situada no município de Campos dos Goytacazes/RJ, e propor melhorias. Porém, para identificar o problema será necessário estabelecer um projeto de análise e solução, com isso, o foco será na Metodologia de Análise e Solução de Problemas (MASP) e nas ferramentas que irão auxiliar neste processo.

A Qualidade Total é formada por um conjunto de Programas, Métodos e Ferramentas, aplicados para se ter o controle do processo e melhoria contínua, bens e serviços com qualidade melhor e custos menores, e consequentemente satisfazer os clientes, superando as expectativas, e gerando eficiência, eficácia e efetividade para a organização (PEREIRA et al., 2011).

\section{REVISÃO BIBLIOGRÁFICA}

\subsection{Panificação}

A panificação se tornou uma verdadeira indústria com os mais diferentes estilos e especialidades, ampliando a proposta inicial das padarias antigamente. 
Com tanta diversidade, o setor de panificação se destaca no país, sua participação no PIB brasileiro é bastante significativa. De acordo com ABIP, ITPC e SEBRAE (2011) o setor de panificação do Brasil é o que possui o maior PIB em relação ao PIB deste ramo no mercado mundial. Além disso, está entre os seis no segmento da indústria, e representam na indústria de produtos alimentares o percentual de $36 \%$ e $6 \%$ da indústria de transformação.

No Brasil, há aproximadamente 63 mil panificadoras, na qual recebem cerca de 44 milhões de clientes, com faturamento estimado R $\$ 39,2$ bilhões, considerando apenas os produtos de fabricação própria, ou seja, sem considerar os produtos de revenda, isso demonstra o quanto elas têm uma parcela de influência na distribuição de renda, pois são geradoras de aproximadamente 802 mil empregos diretos e 1,85 milhões de forma indireta, contribuindo para o desenvolvimento econômico do país (Programa de Desenvolvimento da Alimentação, Confeitaria e Panificação - PROPAN, 2014).

É evidente que a concorrência ficou mais acirrada, as empresas perceberam que para permanecerem no mercado e de forma competitiva, precisam reestruturar a forma administrativa que vem conduzindo o negócio e promover a inovação, mas para isso acontecer a qualidade deve ser alcançada, seja ela no processo e/ou no produto e/ou no serviço, assegurando aos clientes um nível maior de confiabilidade e consequentemente proporcionando o aumento do ticket médio.

\subsection{Gestão da qualidade}

Segundo Slack et al. (2009) a qualidade do produto é a conformidade com as expectativas do cliente. Quando o cliente adquire o produto, ele não está preocupado em analisar como foi feito, de que maneira foi sua produção, o que ele quer é o produto final e que este o satisfaça.

Masiero (2012) observa que o temo qualidade é muito relativo, na qual seu significado pode ser "coisas distintas para diferentes pessoas ou em diferentes lugares, dependendo das necessidades e desejos dos clientes".

Para Garvin (2002) há oito dimensões de qualidade que são:

- Desempenho: está relacionado com os aspectos operacionais básicos de um produto, um exemplo clássico é referente ao funcionamento básico do carro;

- Característica: são os atributos secundários, que suplementam o funcionamento do produto. São os itens a mais. Ex.: Os acessórios do carro;

- Confiabilidade: reflete na probabilidade do produto apresentar falhas, defeitos, quebrar, entre outros. Ou seja, o produto é confiável quando apresenta o mínimo de falhas;

- Conformidade: após a definição do padrão a ser seguido, esta dimensão verifica se o projeto e as características operacionais do produto estão em conformidade com estes (padrões);

- Durabilidade: está relacionado com a vida útil do produto, verifica o tempo do produto até sua deterioração;

- Atendimento: engloba todo o atendimento que o cliente recebe, não está relacionado somente ao ato da compra, mas também no pré venda e pós venda. Engloba a cortesia, agilidade, pontualidade, etc;

- Estética: Apresentação do produto, sua aparência. É a cor, a embalagem chamativa, o formato, o cheiro, ...; 
- Qualidade Percebida: é a percepção do cliente em relação a imagem da empresa, a qualidade é baseada na "reputação" da empresa, ou seja, o cliente avalia a qualidade com base no histórico da empresa, dos seus produtos anteriores. Um exemplo antigo é a marca Brastemp com seu bordão: "Não é assim uma Brastemp", quando compara as outras marcas com a Brastemp, como se estas não tivessem a qualidade Brastemp, e ainda hoje, muitas pessoas compram da Brastemp devido ser referência em qualidade.

Evidencia-se que a qualidade é decisiva sob o ponto de vista da satisfação do cliente, e que consequentemente, é fator chave para as empresas. Ishikawa (1993) afirma que todos os departamentos/setores da empresa e todos os funcionários devem participar do controle de qualidade, para que haja a garantia da qualidade.

A qualidade está inserida neste trabalho, com a Metodologia de Análise e Solução de Problemas e suas ferramentas.

\subsection{MASP}

A metodologia MASP também é conhecida como QC Story, Método PDCA de Melhoria e Método de solução de problemas e é "aplicado de forma sistemática contra uma situação insatisfatória ou para atingimento de um objetivo de melhoria estabelecido" (ARIOLI, 1998 apud PIECHNICKI ; KOVALESKI, 2011).

Hosken (2014) afirma que o problema é decorrente do resultado indesejável de um trabalho, mas é possível sua solução, através das análises das relações entre características e causas de um problema, executando ações corretivas apropriadas. Ou seja, é um "procedimento utilizado para a resolução de problemas [...] que segue uma sequência lógica, começando pela identificação do problema, continuando pela análise e terminando com a tomada de decisão" (HOSKEN, 2014).

Para gerar melhorias, um grupo de pessoas deve ser envolvido para tomar decisões, visando à qualidade dos produtos e serviços (ARIOLI, 1998 apud PIECHNICKI ; KOVALESKI, 2011).

O quadro 1 mostra a sequência do MASP com relação ao PDCA proposta por Campos.

\begin{tabular}{|c|c|c|c|}
\hline PDCA & $\begin{array}{l}\text { Fluxo- } \\
\text { grama }\end{array}$ & Fase & Objetivo \\
\hline \multirow[t]{4}{*}{$\mathbf{P}$} & $\rightarrow 1$ & Identificação do problema & $\begin{array}{l}\text { Definir claramente o problema e reconhecer } \\
\text { sua importância }\end{array}$ \\
\hline & 2 & Observação & $\begin{array}{l}\text { Investigar as características específicas do } \\
\text { problema com uma visão ampla e sob vários } \\
\text { pontos de vista }\end{array}$ \\
\hline & 3 & Análise & Descobrir as causas fundamentais \\
\hline & 4 & Plano de ação & $\begin{array}{l}\text { Conceber um plano para bloquear as causas } \\
\text { fundamentais }\end{array}$ \\
\hline D & 5 & Ação & Bloquear as causas fundamentais \\
\hline \multirow[t]{2}{*}{$\mathbf{C}$} & 6 & Verificação & Verificar se o bloqueio foi efetivo \\
\hline & $\mathrm{N}$ & Bloqueio foi efetivo? & \\
\hline
\end{tabular}




\begin{tabular}{|c|c|l|l|}
\hline A & 7 & Padronização & $\begin{array}{l}\text { Prevenir contra o reaparecimento do } \\
\text { problema }\end{array}$ \\
\cline { 2 - 4 } & 8 & Conclusão & $\begin{array}{l}\text { Recapitular todo o processo de solução do } \\
\text { problema para trabalho futuro. }\end{array}$ \\
\hline
\end{tabular}

Quadro 1 - Sequência do MASP segundo Campos

Fonte: Campos (2004)

Na primeira fase o problema deve ser definido claramente e sua importância deve ser reconhecida. Após a identificação do problema, este deve ser investigado, suas características devem ser analisadas com uma visão ampla e sob vários ângulos. Depois deve descobrir as causas fundamentais. Elaborar um plano de ação para bloquear as causas fundamentais. Excluir as causas fundamentais. Averiguar se o bloqueio foi efetivo, se a ações implantadas foram capazes de bloquear o problema. A etapa seguinte previne contra o reaparecimento do problema, ou seja, é fazer tornar padrão, sendo executado sempre da mesma maneira. A última etapa, tem como objetivo recapitular todo o processo de solução do problema para trabalho futuro, sendo possível analisar tudo o que ocorreu.

\subsection{Ferramentas da qualidade}

Para aplicar o MASP, é necessária a utilização das ferramentas de qualidade. Campos (2004) afirma que método é um conjunto de princípios estipulados para a execução de processos de trabalhos ou atividades, já as ferramentas são os instrumentos, ou seja, é a técnica que se usa para atingir determinados objetivos.

As ferramentas apoiam e auxiliam na tomada de decisão e como consequentemente na busca da qualidade. As ferramentas utilizadas no estudo são:

\section{a) Brainstorming}

Vilaça et al (2010), Mazzotti, Broega e Gomes (2012), e Hosken (2014) informam que o Brainstorming é um processo em que os participantes de uma reunião emitem suas ideias, e para que não tenha inibições, medos e receios, não pode ter críticas e/ou julgamentos, independente da ideia apresentada no decorrer da sua exposição, e todos os pontos abordados são anotados na íntegra pelo coordenador/condutor da reunião, sem que aja exclusão. Durante sua execução, as pessoas devem se sentir confortável em exporem e devem ser estimuladas a todo o momento.

Esta ferramenta estimula a criatividade e a exposição de ideias, e não determina a solução, mas traz consigo um quantitativo de sugestões para determinar o que está ocasionando o problema. Ou seja, quanto maior o número de ideias, melhor é a análise (Hosken, 2014);

\section{b) Diagrama de Causa e Efeito}

Também conhecido como "espinha de peixe" ou diagrama de Ishikawa. Masiero (2012) afirma que este diagrama "é usado para representar o processo de trabalho como um conjunto de atividades, resultando em um produto ou evento final". Visualmente parece com uma espinha de peixe, na qual "as linhas de atividades principais são construídas ao longo de resultados e atividades secundárias, em linhas mais curtas ao longo das principais" (MASIERO, 2012).

De acordo com Amorim e Rocha (2012) esta ferramenta é utilizada quando precisa identificar as causas de um problema, completam que "o diagrama permite, a partir dos grupos básicos de possíveis causas, desdobrar tais causas até os níveis de detalhe adequados à solução do problema", normalmente, para problemas de natureza operacional, os grupos básicos são: máquinas; mão de obra; instalações/ambiente; metodologias/métodos e materiais.

Esta ferramenta analisa, identifica e demonstra visualmente as possíveis causas para um determinado problema/efeito, na qual as causas são agrupadas quando há semelhanças (UNIVERSIDADE DE SÃO PAULO, 2014); 


\section{c) $5 \mathrm{~W} 1 \mathrm{H}$}

Esta ferramenta responde a cinco perguntas, que são: What? - O quê? , define a etapas; Who? Quem? Delega a responsabilidade; When? - Quando? Define o tempo que aquela etapa irá durar; Where? Onde? O local que será feito; Why? - Por quê? É a justificativa; How? - Como? Método que define como será feito as tarefas.

Leusin et al. (2013) afirmam que esta ferramenta "estrutura ações em um plano de contramedidas que objetivam bloquear os pontos críticos identificados no processo".

A elaboração do $5 \mathrm{~W} 1 \mathrm{H}$ tem o intuito de listar ações para a futura elaboração de um projeto mais detalhado (ROVERI et al., 2012).

Hosken (2014) descreve que é um documento na qual é possível identificar as ações e a responsabilidade de cada um de maneira organizada, além de permitir o planejamento das diversas ações que serão desenvolvidas no decorrer do trabalho.

\section{ESTUDO DE CASO}

A panificação em estudo foi criada em 1993, no início das atividades o número de funcionários era bem reduzido, com o passar dos anos a empresa foi se fortalecendo no mercado, o que foi possível melhorar sua estrutura física e de pessoal.

Para toda e qualquer empresa, independente do ramo e de sua classificação, alguns itens/atividades são essenciais, como: higiene, padronização de processos e produtos, atendimento diferenciado, controle, "layout", entre outros. Com isso é importante salientar o quão a gestão da qualidade é primordial.

Com a consolidação no mercado com o passar dos anos, os 23 anos resultaram uma acomodação que teve influencia no baixo faturamento. O estudo é verificar o que está ocasionando a redução do faturamento utilizando a Metodologia para Análise e Solução de Problemas (MASP) para identificar os problemas que estão levando a perda considerável no rendimento financeiro e propor melhorias.

O primeiro passo foi conhecer a empresa em estudo, foi feito um levantamento da vida financeira, verificando quais dados ela tinha disponível para fazer uma análise histórica. Como segunda etapa do procedimento metodológico, foram feitas as observações com relação a estrutura físicas e o funcionamento do estabelecimento em detrimento das alocações físicas.

A terceira etapa foi a realização do "Brainstorming" com todos os funcionários, que foram incentivados a exporem suas ideias sobre as causas e possíveis soluções para o objeto em estudo, independente das atividades por eles realizadas na empresa e sem a preocupação de críticas e julgamento dos demais. Após a exposição de várias ideias, foi aplicado um questionário aberto, pois, por mais que a reunião tenha sido produtiva, pode ser que algumas pessoas não tenham exposto tudo o que queriam, talvez por medo em expor determinados assuntos para os colegas e serem mau visto pelo grupo.

Os clientes também fizeram parte da análise deste estudo, com a aplicação dos questionários abertos. O motivo de ter sido dois públicos distintos (clientes e funcionários), se deu devido as percepções diferentes e Silva et al. (2012) justificativa que é “ em função do perfil do cliente em sua tendência de apontar características negativas, enquanto os funcionários tendem a assinalar pontos positivos dos serviços".

As respostas do questionário aberto, serviram de base para a elaboração do questionário fechado, ou seja, "com o objetivo de captar a percepção com relação aos pontos fortes e fracos dos produtos e serviços oferecidos" (SILVA et al., 2012), na qual dados semelhantes foram agrupados.

Após análise, a quarta etapa foi iniciada, com a aplicação dos questionários fechados aos clientes, nos quais responderam anonimamente e a escolha foi de forma aleatória. O questionário captou a percepção 
dos clientes em relação a panificação de uma maneira geral, quanto a frequência, e o grau de importância e satisfação das instalações, dos produtos e serviços da panificação, além dos dados pessoais.

A escala utilizada foi a de Likert e verificou-se que quantidade ideal para aplicar o questionário final aos clientes é de 150 (margem de erro de até $8 \%$ ) e no de funcionários não houve margem de erro, pois todos responderam.

Através dos dados obtidos em decorrência dos questionários aplicados, foi possível aplicar métodos estatísticos, sendo estes: satisfação simples, análise do GAP e a abordagem multiplicativa (insatisfação ponderada), e elencar os problemas diagnosticados, como também foi possível elaborar o diagrama de causaefeito.

Com este diagrama foi feito outra reunião com os funcionários para ver como iria resolver os problemas e montar um plano de ação que constitui a quinta e última etapa desta metodologia. Para a elaboração deste plano utilizou-se da ferramenta $5 \mathrm{~W} 1 \mathrm{H}$ para estabelecer uma proposta de ação para bloquear as causas do problema em estudo.

\section{RESULTADOS}

A tabela 1 faz a comparação dos 3 métodos estatísticos baseado nos questionários aplicados.

Tabela 1 - Comparação dos Métodos

\begin{tabular}{|c|c|c|c|c|c|}
\hline \multicolumn{2}{|l|}{ Satisfação Simples } & \multicolumn{2}{|l|}{ GAP } & \multicolumn{2}{|c|}{$\begin{array}{c}\text { Abordagem Multiplicativa } \\
\text { (Insatisfação Ponderada) }\end{array}$} \\
\hline Descrição & $\bar{X}$ & Descrição & $\bar{X}$ & Descrição & $\bar{X}$ \\
\hline $\begin{array}{l}\text { 5.6. Forma de Pagamento } \\
\text { (Cartão) }\end{array}$ & 1,85 & $\begin{array}{l}\text { 5.6. Forma de Pagamento } \\
\text { (Cartão) }\end{array}$ & 2,63 & $\begin{array}{l}\text { 5.6. Forma de } \\
\text { Pagamento (Cartão) }\end{array}$ & 14,09 \\
\hline $\begin{array}{l}\text { 3.2. Proximidade do } \\
\text { Trabalho }\end{array}$ & 2,25 & 3.10. Climatização & 1,48 & 3.10. Climatização & 9,37 \\
\hline 3.10. Climatização & 2,82 & $\begin{array}{l}\text { 5.2. Tempo de espera do } \\
\text { atendimento do caixa }\end{array}$ & 1,30 & $\begin{array}{l}\text { 4.21. Variedade dos } \\
\text { produtos congelados } \\
\text { de fabricação própria }\end{array}$ & 8,21 \\
\hline $\begin{array}{l}\text { 4.21. Variedade dos } \\
\text { produtos congelados de } \\
\text { fabricação própria }\end{array}$ & 2,91 & $\begin{array}{l}\text { 4.21. Variedade dos } \\
\text { produtos congelados de } \\
\text { fabricação própria }\end{array}$ & 1,02 & $\begin{array}{l}\text { 5.2. Tempo de espera } \\
\text { do atendimento do } \\
\text { caixa }\end{array}$ & 6,93 \\
\hline $\begin{array}{l}\text { 4.22. Porção dos produtos } \\
\text { fabricados }\end{array}$ & 2,98 & 4.2. Preço & 0,92 & $\begin{array}{l}\text { 4.22. Porção dos } \\
\text { produtos fabricados }\end{array}$ & 6,75 \\
\hline 3.7. Bicicletário & 3,17 & 4.4. Promoção & 0,82 & 3.9. Espaço da loja & 6,55 \\
\hline $\begin{array}{l}\text { 3.4. Facilidade de } \\
\text { Estacionamento }\end{array}$ & 3,20 & $\begin{array}{l}\text { 5.7. Aparência (Higiene, } \\
\text { Limpeza, Vestimenta) dos } \\
\text { funcionários }\end{array}$ & 0,82 & 4.2. Preço & 6,45 \\
\hline 4.3. Embalagem & 3,20 & 3.8. Limpeza e Higiene & 0,72 & 4.4. Promoção & 6,42 \\
\hline 4.29. Variedade de Cigarro & 3,31 & 4.17. Variedade das tortas & 0,64 & 4.3. Embalagem & 6,34 \\
\hline 3.9. Espaço da loja & 3,32 & $\begin{array}{l}\text { 4.12. Qualidade dos bolos } \\
\text { confeitados }\end{array}$ & 0,61 & $\begin{array}{l}\text { 4.17. Variedade das } \\
\text { tortas }\end{array}$ & 6,32 \\
\hline
\end{tabular}




\begin{tabular}{|c|c|c|c|c|c|}
\hline $\begin{array}{l}\text { 4.13. Variedade dos bolos } \\
\text { confeitados }\end{array}$ & 3,35 & 3.9. Espaço da loja & 0,58 & $\begin{array}{l}\text { 5.7. Aparência } \\
\text { (Higiene, Limpeza, } \\
\text { Vestimenta) dos } \\
\text { funcionários }\end{array}$ & 5,94 \\
\hline 4.17. Variedade das tortas & 3,46 & $\begin{array}{l}\text { 4.1. Apresentação dos } \\
\text { produtos }\end{array}$ & 0,56 & $\begin{array}{l}\text { 4.13. Variedade dos } \\
\text { bolos confeitados }\end{array}$ & 5,93 \\
\hline $\begin{array}{l}\text { 4.15. Variedade dos doces } \\
\text { caseiros de fabricação } \\
\text { própria }\end{array}$ & 3,50 & 3.5. Ambiente Agradável & 0,52 & $\begin{array}{l}\text { 4.12. Qualidade dos } \\
\text { bolos confeitados }\end{array}$ & 5,62 \\
\hline $\begin{array}{l}\text { 4.27. Variedade de } \\
\text { produtos de conveniência }\end{array}$ & 3,52 & 4.16. Qualidade das tortas & 0,50 & $\begin{array}{l}\text { 4.16. Qualidade das } \\
\text { tortas }\end{array}$ & 5,55 \\
\hline $\begin{array}{l}\text { 4.28. Variedade de } \\
\text { produtos de Mercearia }\end{array}$ & 3,52 & $\begin{array}{l}\text { 5.4. Qualidade no } \\
\text { atendimento dos atendentes } \\
\text { do balcão }\end{array}$ & 0,48 & $\begin{array}{l}\text { 4.15. Variedade dos } \\
\text { doces caseiros de } \\
\text { fabricacão própria }\end{array}$ & 5,54 \\
\hline 4.4. Promoção & 3,54 & $\begin{array}{l}\text { 5.1. Tempo de espera no } \\
\text { atendimento do balcão }\end{array}$ & 0,44 & $\begin{array}{l}\text { 3.2. Proximidade do } \\
\text { Trabalho }\end{array}$ & 5,45 \\
\hline 4.2. Preço & 3,56 & $\begin{array}{l}\text { 4.22. Porção dos produtos } \\
\text { fabricados }\end{array}$ & 0,36 & $\begin{array}{l}\text { 3.8. Limpeza e } \\
\text { Higiene }\end{array}$ & 5,15 \\
\hline $\begin{array}{l}\text { 5.2. Tempo de espera do } \\
\text { atendimento do caixa }\end{array}$ & 3,58 & 4.3. Embalagem & 0,32 & 3.7. Bicicletário & 5,14 \\
\hline 4.16. Qualidade das tortas & 3,67 & $\begin{array}{l}\text { 4.13. Variedade dos bolos } \\
\text { confeitados }\end{array}$ & 0,25 & $\begin{array}{l}\text { 4.19. Variedade dos } \\
\text { Salgados }\end{array}$ & 4,79 \\
\hline $\begin{array}{l}\text { 5.7. Aparência (Higiene, } \\
\text { Limpeza, Vestimenta) dos } \\
\text { funcionários }\end{array}$ & 3,68 & $\begin{array}{l}\text { 4.20. Qualidade dos } \\
\text { produtos congelados de } \\
\text { fabricação própria }\end{array}$ & 0,21 & $\begin{array}{l}\text { 3.5. Ambiente } \\
\text { Agradável }\end{array}$ & 4,52 \\
\hline $\begin{array}{l}\text { 4.12. Qualidade dos bolos } \\
\text { confeitados }\end{array}$ & 3,69 & $\begin{array}{l}\text { 5.5. Qualidade no } \\
\text { atendimento dos atendentes } \\
\text { do caixa }\end{array}$ & 0,20 & $\begin{array}{l}\text { 4.29. Variedade de } \\
\text { Cigarro }\end{array}$ & 4,51 \\
\hline $\begin{array}{l}\text { 4.19. Variedade dos } \\
\text { Salgados }\end{array}$ & 3,77 & $\begin{array}{l}\text { 4.15. Variedade dos doces } \\
\text { caseiros de fabricação } \\
\text { própria }\end{array}$ & 0,19 & $\begin{array}{l}\text { 4.20. Qualidade dos } \\
\text { produtos congelados } \\
\text { de fabricação própria }\end{array}$ & 4,41 \\
\hline 4.24. Variedade de Bebidas & 3,78 & $\begin{array}{l}\text { 3.1. Proximidade da } \\
\text { Residência }\end{array}$ & 0,18 & $\begin{array}{l}\text { 4.24. Variedade de } \\
\text { Bebidas }\end{array}$ & 4,37 \\
\hline 3.8. Limpeza e Higiene & 3,88 & $\begin{array}{l}\text { 4.8. Qualidade dos pães de } \\
\text { pacote }\end{array}$ & 0,16 & $\begin{array}{l}\text { 4.1. Apresentação dos } \\
\text { produtos }\end{array}$ & 4,27 \\
\hline $\begin{array}{l}\text { 4.14. Qualidade dos doces } \\
\text { caseiros de fabricação } \\
\text { própria }\end{array}$ & 3,91 & $\begin{array}{l}\text { 4.18. Qualidade dos } \\
\text { Salgados }\end{array}$ & 0,13 & $\begin{array}{l}\text { 4.14. Qualidade dos } \\
\text { doces caseiros de } \\
\text { fabricação própria }\end{array}$ & 4,23 \\
\hline $\begin{array}{l}\text { 4.31. Variedade de } \\
\text { produtos Congelados }\end{array}$ & 3,92 & $\begin{array}{l}\text { 4.19. Variedade dos } \\
\text { Salgados }\end{array}$ & 0,10 & $\begin{array}{l}\text { 4.31. Variedade de } \\
\text { produtos Congelados }\end{array}$ & 4,14 \\
\hline $\begin{array}{l}\text { 4.20. Qualidade dos } \\
\text { produtos congelados de } \\
\text { fabricação própria }\end{array}$ & 3,94 & $\begin{array}{l}\text { 5.3. Cordialidade do Sócio } \\
\text { proprietário }\end{array}$ & 0,10 & $\begin{array}{l}\text { 3.4. Facilidade de } \\
\text { Estacionamento }\end{array}$ & 3,89 \\
\hline 3.5. Ambiente Agradável & 4,00 & $\begin{array}{l}\text { 4.9. Variedade dos pães de } \\
\text { pacote }\end{array}$ & 0,07 & $\begin{array}{l}\text { 4.18. Qualidade dos } \\
\text { Salgados }\end{array}$ & 3,83 \\
\hline $\begin{array}{l}\text { 4.1. Apresentação dos } \\
\text { produtos }\end{array}$ & 4,08 & $\begin{array}{l}\text { 4.14. Qualidade dos doces } \\
\text { caseiros de fabricação } \\
\text { própria }\end{array}$ & $-0,02$ & $\begin{array}{l}4.27 . \text { Variedade de } \\
\text { produtos de } \\
\text { conveniência }\end{array}$ & 3,53 \\
\hline $\begin{array}{l}\text { 4.18. Qualidade dos } \\
\text { Salgados }\end{array}$ & 4,09 & $\begin{array}{l}\text { 4.31. Variedade de } \\
\text { produtos Congelados }\end{array}$ & $-0,10$ & $\begin{array}{l}\text { 3.1. Proximidade da } \\
\text { Residência }\end{array}$ & 3,50 \\
\hline $\begin{array}{l}\text { 4.25. Variedade de } \\
\text { Laticínios }\end{array}$ & 4,18 & $\begin{array}{l}\text { 4.6. Qualidade dos pães } \\
\text { doces }\end{array}$ & $-0,10$ & $\begin{array}{l}\text { 4.28. Variedade de } \\
\text { produtos de Mercearia }\end{array}$ & 3,29 \\
\hline
\end{tabular}




\begin{tabular}{|c|c|c|c|c|c|}
\hline $\begin{array}{l}\text { 3.1. Proximidade da } \\
\text { Residência }\end{array}$ & 4,20 & $\begin{array}{l}\text { 4.7. Variedade dos pães } \\
\text { doces }\end{array}$ & $-0,14$ & $\begin{array}{l}\text { 4.8. Qualidade dos } \\
\text { pães de pacote }\end{array}$ & 2,97 \\
\hline 4.26. Variedade de Frios & 4,21 & $\begin{array}{l}\text { 4.5. Qualidade do pão de } \\
\text { sal }\end{array}$ & $-0,16$ & $\begin{array}{l}\text { 5.4. Qualidade no } \\
\text { atendimento dos } \\
\text { atendentes do balcão }\end{array}$ & 2,93 \\
\hline $\begin{array}{l}\text { 4.23. Variedade de } \\
\text { Bomboniere }\end{array}$ & 4,24 & 4.24. Variedade de Bebidas & $-0,20$ & $\begin{array}{l}\text { 4.25. Variedade de } \\
\text { Laticínios }\end{array}$ & 2,90 \\
\hline $\begin{array}{l}\text { 4.10. Qualidade dos bolos } \\
\text { comuns }\end{array}$ & 4,30 & $\begin{array}{l}\text { 4.10. Qualidade dos bolos } \\
\text { comuns }\end{array}$ & $-0,24$ & $\begin{array}{l}\text { 4.10. Qualidade dos } \\
\text { bolos comuns }\end{array}$ & 2,85 \\
\hline $\begin{array}{l}\text { 4.8. Qualidade dos pães de } \\
\text { pacote }\end{array}$ & 4,34 & $\begin{array}{l}\text { 3.2. Proximidade do } \\
\text { Trabalho }\end{array}$ & $-0,27$ & $\begin{array}{l}\text { 4.26. Variedade de } \\
\text { Frios }\end{array}$ & 2,79 \\
\hline $\begin{array}{l}\text { 5.4. Qualidade no } \\
\text { atendimento dos atendentes } \\
\text { do balcão }\end{array}$ & 4,40 & 3.7. Bicicletário & $-0,36$ & $\begin{array}{l}\text { 5.1. Tempo de espera } \\
\text { no atendimento do } \\
\text { balcão }\end{array}$ & 2,73 \\
\hline $\begin{array}{l}\text { 5.1. Tempo de espera no } \\
\text { atendimento do balcão }\end{array}$ & 4,44 & $\begin{array}{l}\text { 4.11. Variedade dos bolos } \\
\text { comuns }\end{array}$ & $-0,37$ & $\begin{array}{l}\text { 4.9. Variedade dos } \\
\text { pães de pacote }\end{array}$ & 2,41 \\
\hline $\begin{array}{l}\text { 4.9. Variedade dos pães de } \\
\text { pacote }\end{array}$ & 4,47 & $\begin{array}{l}\text { 4.25. Variedade de } \\
\text { Laticínios }\end{array}$ & $-0,63$ & $\begin{array}{l}\text { 4.23. Variedade de } \\
\text { Bomboniere }\end{array}$ & 2,40 \\
\hline 3.3. Iluminação & 4,62 & 4.29. Variedade de Cigarro & $-0,65$ & $\begin{array}{l}\text { 5.3. Cordialidade do } \\
\text { Sócio proprietário }\end{array}$ & 1,69 \\
\hline $\begin{array}{l}\text { 5.3. Cordialidade do Sócio } \\
\text { proprietário }\end{array}$ & 4,64 & 4.26. Variedade de Frios & $-0,69$ & $\begin{array}{l}5.5 . \text { Qualidade no } \\
\text { atendimento dos } \\
\text { atendentes do caixa }\end{array}$ & 1,65 \\
\hline $\begin{array}{l}\text { 4.6. Qualidade dos pães } \\
\text { doces }\end{array}$ & 4,64 & 3.3. Iluminação & $-0,07$ & $\begin{array}{l}\text { 4.6. Qualidade dos } \\
\text { pães doces }\end{array}$ & 1,63 \\
\hline $\begin{array}{l}\text { 5.5. Qualidade no } \\
\text { atendimento dos atendentes } \\
\text { do caixa }\end{array}$ & 4,66 & $\begin{array}{l}\text { 3.6. Horário de } \\
\text { Funcionamento }\end{array}$ & $-0,72$ & 3.3. Iluminação & 1,49 \\
\hline $\begin{array}{l}\text { 4.11. Variedade dos bolos } \\
\text { comuns }\end{array}$ & 4,69 & 4.30. Variedade de Sorvete & $-0,74$ & $\begin{array}{l}\text { 4.11. Variedade dos } \\
\text { bolos comuns }\end{array}$ & 1,35 \\
\hline $\begin{array}{l}\text { 3.6. Horário de } \\
\text { Funcionamento }\end{array}$ & 4,84 & $\begin{array}{l}\text { 3.4. Facilidade de } \\
\text { Estacionamento }\end{array}$ & $-1,04$ & $\begin{array}{l}\text { 4.7. Variedade dos } \\
\text { pães doces }\end{array}$ & 0,75 \\
\hline $\begin{array}{l}\text { 4.7. Variedade dos pães } \\
\text { doces }\end{array}$ & 4,84 & $\begin{array}{l}\text { 4.23. Variedade de } \\
\text { Bomboniere }\end{array}$ & $-1,06$ & $\begin{array}{l}\text { 3.6. Horário de } \\
\text { Funcionamento }\end{array}$ & 0,66 \\
\hline 4.30. Variedade de Sorvete & 4,86 & $\begin{array}{l}\text { 4.27. Variedade de } \\
\text { produtos de conveniência }\end{array}$ & $-1,12$ & $\begin{array}{l}\text { 4.30. Variedade de } \\
\text { Sorvete }\end{array}$ & 0,58 \\
\hline $\begin{array}{l}\text { 4.5. Qualidade do pão de } \\
\text { sal }\end{array}$ & 4,92 & $\begin{array}{l}\text { 4.28. Variedade de } \\
\text { produtos de Mercearia }\end{array}$ & $-1,30$ & $\begin{array}{l}\text { 4.5. Qualidade do pão } \\
\text { de sal }\end{array}$ & 0,38 \\
\hline
\end{tabular}

Fonte: Elaborado pelos autores com base nos dados da pesquisa de campo.

Esta tabela mostra que independente do método, a "Forma de Pagamento (Cartão)" foi considerado em primeiro lugar, como um item que deve ser avaliado com extrema urgência pela empresa, os itens "Climatização", e "Variedade dos produtos congelado de fabricação própria" estão entre os 4 primeiros .

O item "tempo de espera do caixa", apareceu entre os quatros primeiros para o método GAP e Insatisfação Ponderada. O item "porção dos produtos fabricados" também merece ser reavaliado pela empresa.

Essa pesquisa ampliou o leque de possibilidades no que está interferindo no rendimento financeiro da panificação em estudo. Houve outra reunião para apresentar o resultado da pesquisa e apurar as causas, sendo então possível elaborar o diagrama de Ishikawa como mostra a figura 1. 


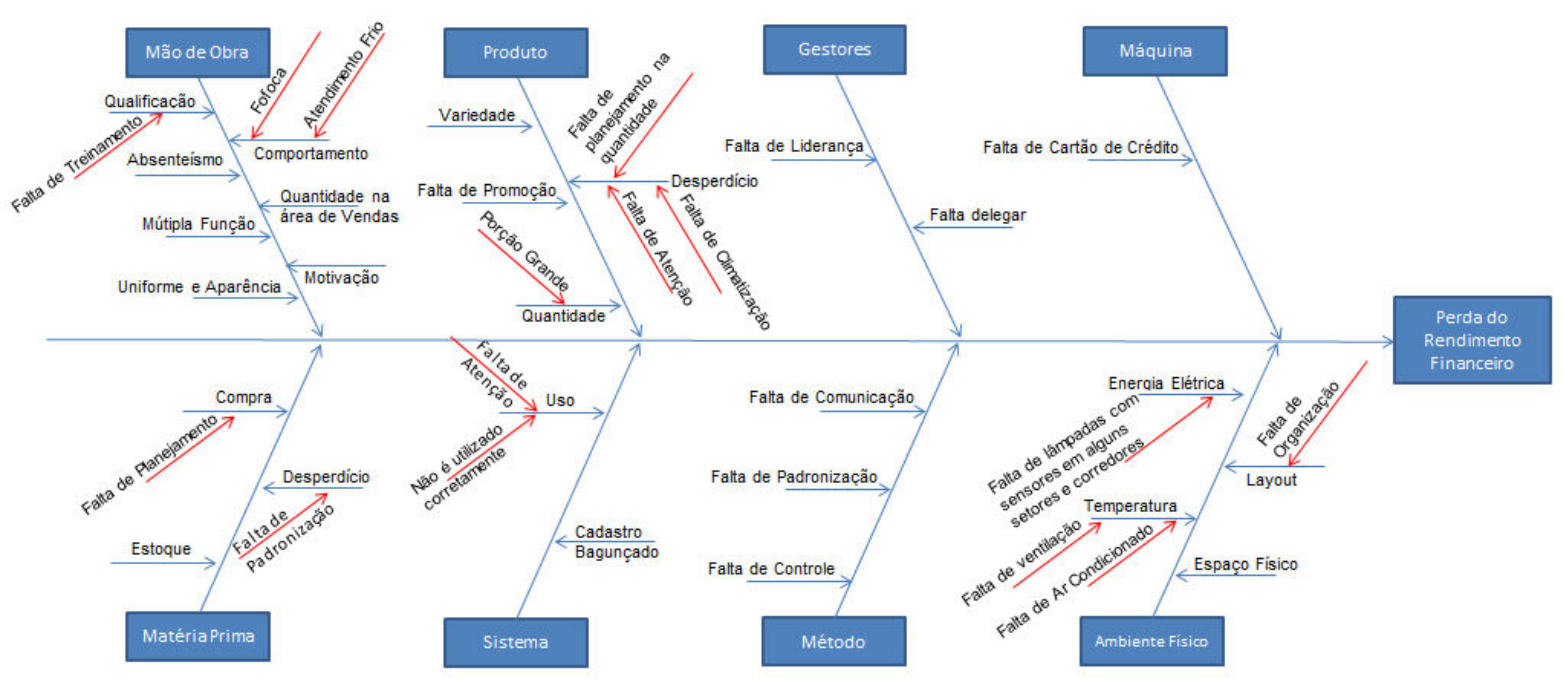

Figura 1 - Diagrama de causa e efeito

Fonte: Elaborado pelos autores e pelos colaboradores da empresa com base nos dados da pesquisa aplicada aos clientes e no Brainstorming.

As possíveis causas apuradas foram vinculadas a Mão-de-obra, Produto, Gestores, Máquina, Matéria prima, Sistema, Método e Ambiente físico. Destas causas, às relacionadas mão de obra, máquina e produtos foram escolhidas como prioridade, por serem as que mais impactam negativamente no resultado financeiro da empresa.

Hoje, o Cartão de crédito é muito utilizado, muitas pessoas possuem e só compram com eles, conforme conversa com as atendentes de caixa, elas confirmaram dizendo que muitos clientes vão para comprar o básico, as vezes o pão de sal, e quando chegam na panificação se deparam com algo que gostam e não tem como comprar, pois o dinheiro em espécie que foi levado não da para comprar o "a mais", e muito das vezes não retornam, com isso a panificação deixa de vender o que comprova com a prática, necessitando de no mínimo mais um funcionário. Com o aumento de funcionário é mais gasto, mas é um gasto necessário, nem que seja em momentos de picos.

Com relação a climatização como reclamação por parte dos clientes, pode ser que eles estejam insatisfeitos por conta do tempo que se leva para pagar, talvez se tiver mais um caixa, este item não ganhe destaque, pois o cliente ficará menos tempo na loja. Mas de qualquer maneira, a falta de climatização afeta na qualidade dos produtos, pois a cidade de Campos dos Goytacazes tem elevado grau de temperatura, com isso, os produtos que são perecíveis se deterioram mais rápido.

As famílias de hoje estão cada vez menores, pode ser que determinados produtos são deixados de vender por conta disso, pois a porção oferecida dos produtos (pães de pacotes, tamanhos do s bolos, etc.) é para famílias maiores.

O item de falta de treinamento é fundamental, pois interfere diretamente na qualidade do atendimento e no comportamento. A aparência também é importante, todos os funcionários têm uniformes, mas não utilizam regularmente. A motivação está baixa, necessitando ser avaliado.

Com relação a múltipla função há somente um caso, pois a pessoa que atua na pré-pesagem/estoque é solicita para atuar no atendimento do balcão em horários de pico, com isso as vezes chega mercadoria e ela vai atender o fornecedor correndo, deixando descoberto o atendimento e não conferindo os produtos como deveria. 
A princípio o que tem que ser revisto é a variedade dos produtos congelados de fabricação própria, com a correria do dia a dia, as pessoas estão optando em comprar produtos de fácil consumo, sem necessitar a saída de sua residência em momentos inoportunos.

Um dos itens que gera desperdício de produto acabado é o excesso da quantidade de fabricação de alguns produtos. Não há um planejamento diário baseado em recortes temporais, o que aumenta a probabilidade de acontecer erros, e como todo e qualquer planejamento é passível de erro, nestes casos nada que uma promoção não resolva, impossibilitando o vencimento dos produtos.

A falta de atenção na organização dos produtos nas prateleiras também é grande, colocam os produtos mais novos na frente dos antigos.

Após este levantamento, a equipe elaborou um plano de ação para atacar estas causas e a ferramenta que auxiliou nesta etapa foi a $5 \mathrm{~W} 1 \mathrm{H}$ que está disponível no quadro 2 . 


\begin{tabular}{|c|c|c|c|c|c|c|}
\hline Itens & $\begin{array}{c}\text { WHAT? } \\
\text { (O que será feito?) }\end{array}$ & $\begin{array}{l}\text { WHEN? } \\
\text { (Quando será } \\
\text { feito?) }\end{array}$ & $\begin{array}{l}\text { WHERE? } \\
\text { (Onde será } \\
\text { feito?) }\end{array}$ & $\begin{array}{c}\text { WHY? } \\
\text { (Por que será feito?) }\end{array}$ & $\begin{array}{c}\text { WHO? } \\
\text { (Quem fará?) }\end{array}$ & $\begin{array}{c}\text { HOW? } \\
\text { (Como será feito?) }\end{array}$ \\
\hline $\begin{array}{l}\text { Qualificação } \\
\text { Motivação } \\
\text { Absenteísmo }\end{array}$ & $\begin{array}{l}\text { Procurar o Sebrae e o } \\
\text { Sindicato para } \\
\text { proporcionar palestras } \\
\text { e cursos para a área } \\
\text { motivacional e de } \\
\text { aperfeiçoamento }\end{array}$ & $17 / 03 / 2016$ & $\begin{array}{c}\text { Nas } \\
\text { instalações } \\
\text { do Sebrae e } \\
\text { do Sindicato }\end{array}$ & $\begin{array}{l}\text { Os cursos irão } \\
\text { melhorar a qualidade } \\
\text { no atendimento, o } \\
\text { comportamento e a } \\
\text { valorização do } \\
\text { funcionário. }\end{array}$ & $\begin{array}{l}\text { Sócio } \\
\text { proprietário }\end{array}$ & $\begin{array}{l}\text { Após a parceria, será feito um } \\
\text { calendário de como serão os } \\
\text { cursos. }\end{array}$ \\
\hline $\begin{array}{l}\text { Múltipla } \\
\text { função }\end{array}$ & $\begin{array}{l}\text { Reorganizar a rotina } \\
\text { de trabalho da pessoa } \\
\text { que trabalha no setor } \\
\text { de estoque/pré } \\
\text { pesagem e que auxilia } \\
\text { o atendimento do } \\
\text { balcão em horário de } \\
\text { pico }\end{array}$ & $17 / 03 / 2016$ & Panificação & $\begin{array}{l}\text { A funcionária não } \\
\text { está sabendo lidar } \\
\text { com mais de uma } \\
\text { função. }\end{array}$ & $\begin{array}{l}\text { Gerentes } \\
\text { Funcionária da } \\
\text { pré-pesagem }\end{array}$ & $\begin{array}{l}\text { Os gerentes irão determinar junto } \\
\text { aos fornecedores os horários de } \\
\text { entrega, pois não poderão entregar } \\
\text { a hora que quiserem. } \\
\text { Reorganizar o horário em cada } \\
\text { função. }\end{array}$ \\
\hline $\begin{array}{l}\text { Uniforme e } \\
\text { Aparência }\end{array}$ & Cobrar o uso & $10 / 03 / 2016$ & Panificação & $\begin{array}{lr}\text { Para melhorar } & \text { a } \\
\text { visualização/ } & \\
\text { aparência } & \text { dos } \\
\text { funcionários } & \text { perante } \\
\text { aos clientes e } & \text { por } \\
\text { questão } & \text { de } \\
\text { higienização } & \\
\text { também. } & \\
\end{array}$ & $\begin{array}{l}\text { Gerentes } \\
\text { cobrarão o uso e } \\
\text { os funcionários } \\
\text { usarão os } \\
\text { uniformes que a } \\
\text { empresa entregou } \\
\text { no final do ano } \\
\text { passado. }\end{array}$ & $\begin{array}{l}\text { Diariamente será feito uma vistoria } \\
\text { pelos gerentes. }\end{array}$ \\
\hline $\begin{array}{l}\text { Quantidade de } \\
\text { funcionário na } \\
\text { área de venda }\end{array}$ & $\begin{array}{l}\text { Contratação de no } \\
\text { mínimo mais um } \\
\text { funcionário. }\end{array}$ & $\begin{array}{l}\text { Quando o } \\
\text { balcão e os } \\
\text { equipamentos } \\
\text { de caixa } \\
\text { chegar }\end{array}$ & Panificação & $\begin{array}{lr}\text { Fila grande } & \text { no } \\
\text { momento } & \text { do } \\
\text { pagamento, o que } \\
\text { gera demora } & \text { no } \\
\text { atendimento e } & \text { os }\end{array}$ & $\begin{array}{l}\text { Sócio } \\
\text { proprietário }\end{array}$ & $\begin{array}{l}\text { Será disponibilizada a vaga para } \\
\text { que possa ser feito o recrutamento } \\
\text { e seleção. }\end{array}$ \\
\hline
\end{tabular}

Persp. online: hum. \& sociais aplicada., Campos dos Goytacazes, 18 (7), 01-17, 2017

seer.perspectivasonline.com.br 


\begin{tabular}{|c|c|c|c|c|c|c|c|}
\hline & & & & $\begin{array}{ll}\text { clientes } & \text { ficam } \\
\text { impacientes. } & \\
\end{array}$ & & & \\
\hline $\begin{array}{l}\text { Variedades } \\
\text { dos produtos } \\
\text { congelados de } \\
\text { fabricação } \\
\text { própria }\end{array}$ & $\begin{array}{l}\text { Aumentar o portfólio } \\
\text { destes produtos }\end{array}$ & $01 / 05 / 2016$ & $\begin{array}{l}\text { Produção da } \\
\text { Panificação }\end{array}$ & $\begin{array}{l}\text { A quantidade } \\
\text { oferecida para venda } \\
\text { é pequena, o gera } \\
\text { insatisfação } \\
\text { clientes. }\end{array}$ & $\begin{array}{l}\text { Gerente } \\
\text { Produção, } \\
\text { Padeiros } \\
\text { Confeiteiro }\end{array}$ & de & $\begin{array}{l}\text { Primeiro irão listar o que possuem } \\
\text { juntamente com as receitas; } \\
\text { Depois irão conversar } \\
\text { aleatoriamente com os clientes, o } \\
\text { que eles gostariam de ter como } \\
\text { opção de produtos congelados; } \\
\text { Elaborar as receitas dos pedidos; } \\
\text { Elaboras os custos; } \\
\text { Fazer amostra grátis em local e dia } \\
\text { estratégico. }\end{array}$ \\
\hline $\begin{array}{l}\text { Falta de } \\
\text { Promoção }\end{array}$ & $\begin{array}{l}\text { Fazer promoção de } \\
\text { alguns produtos }\end{array}$ & $15 / 04 / 2016$ & $\begin{array}{l}\text { No setor de } \\
\text { vendas da } \\
\text { panificação }\end{array}$ & $\begin{array}{lr}\text { Tem } & \text { muitos } \\
\text { produtos que não } \\
\text { estão vendendo, e/ } \\
\text { ou estão em } \\
\text { quantidade } \\
\text { excessiva. } \\
\end{array}$ & $\begin{array}{l}\text { Sócio } \\
\text { proprietário }\end{array}$ & & $\begin{array}{l}\text { Verificar quais produtos que estão } \\
\text { ficando mais tempo nas prateleiras. } \\
\text { Lançar um percentual de desconto } \\
\text { ou fazer venda casada com } \\
\text { desconto (ex.: Salgado + Guaravita } \\
=\mathrm{R} \$ \mathrm{XX}, \mathrm{XX})\end{array}$ \\
\hline Porção grande & $\begin{array}{l}\text { Aumentar a variedade } \\
\text { da quantidade da } \\
\text { porção }\end{array}$ & $15 / 05 / 2016$ & $\begin{array}{l}\text { Produção da } \\
\text { panificação }\end{array}$ & $\begin{array}{l}\text { As famílias estão } \\
\text { cada vez mais } \\
\text { reduzidas }\end{array}$ & $\begin{array}{l}\text { Sócio } \\
\text { proprietário } \\
\text { Gerente } \\
\text { Produção }\end{array}$ & de & $\begin{array}{l}\text { Verificar quais fornecedores que } \\
\text { vendem formas; } \\
\text { Verificar quais fornecedores } \\
\text { vendem embalagens menores; } \\
\text { Fazer cotação e comprar; } \\
\text { Para os produtos que são vendidos } \\
\text { a unidades, deverá ser recalculado } \\
\text { o valor de venda. }\end{array}$ \\
\hline Climatização & $\begin{array}{l}\text { Colocar ventilador e } \\
\text { "abrir" janelas }\end{array}$ & $24 / 03 / 2016$ & $\begin{array}{l}\text { No setor de } \\
\text { vendas da } \\
\text { panificação }\end{array}$ & Está muito calor & $\begin{array}{l}\text { Sócio } \\
\text { proprietário } \\
\text { Terceirizado }\end{array}$ & & $\begin{array}{l}\text { Sócio proprietário irá cotar os } \\
\text { preços dos ventiladores, das } \\
\text { grades, telas, e do serviço. } \\
\text { Comprar os materiais e contratar o } \\
\text { serviço. }\end{array}$ \\
\hline
\end{tabular}




\begin{tabular}{|c|c|c|c|c|c|c|}
\hline & & & & & & $\begin{array}{l}\text { O terceirizado irá instalar os } \\
\text { ventiladores e "abrir" janelas }\end{array}$ \\
\hline $\begin{array}{l}\text { Planejamento } \\
\text { da quantidade } \\
\text { de produto } \\
\text { produzido }\end{array}$ & $\begin{array}{l}\text { Estabelecimento de } \\
\text { cronograma para } \\
\text { realização de pedidos } \\
\text { por tipo de material }\end{array}$ & $17 / 03 / 2016$ & Panificação & $\begin{array}{l}\text { Quantidade } \\
\text { fabricada de alguns } \\
\text { itens em excesso. }\end{array}$ & $\begin{array}{lr}\text { Funcionária } & \text { da } \\
\text { Pré-pesagem } & \text { e } \\
\text { Atendente } & \text { de } \\
\text { caixa } & \end{array}$ & $\begin{array}{l}\text { A funcionária da pré-pesagem irá } \\
\text { fazer um histórico de produtos } \\
\text { fabricados; } \\
\text { Verificar a quantidade de } \\
\text { encomenda; } \\
\text { A atendente não deve permitir que } \\
\text { a encomenda seja feita com menos } \\
\text { de } 24 \mathrm{~h} \text {; }\end{array}$ \\
\hline $\begin{array}{l}\text { Falta de } \\
\text { atenção }\end{array}$ & $\begin{array}{l}\text { Conscientização dos } \\
\text { funcionários }\end{array}$ & $24 / 03 / 2016$ & Panificação & $\begin{array}{l}\text { Arrumação errada } \\
\text { nas prateleiras }\end{array}$ & $\begin{array}{l}\text { Funcionários } \\
\text { gerentes }\end{array}$ & $\begin{array}{lrr}\text { Reunião com os funcionários de } \\
\text { vendas para esclarecer como } \\
\text { arrumar os } \\
\text { prateleiras; } & & \\
\text { Fiscalizar; } & & \\
\end{array}$ \\
\hline $\begin{array}{l}\text { Falta de } \\
\text { Cartão de } \\
\text { Crédito }\end{array}$ & $\begin{array}{lr}\text { Comprar a máquina e } \\
\text { adquirir } \\
\text { telefônica }\end{array}$ & $01 / 05 / 2016$ & Panificação & $\begin{array}{l}\text { Falta de opção de } \\
\text { pagamento }\end{array}$ & Sócio gerente & $\begin{array}{l}\text { Cotar os preços oferecidos para } \\
\text { aquisição de linha telefônica; } \\
\text { Adquirir a linha e a máquina; }\end{array}$ \\
\hline Fofoca & $\begin{array}{l}\text { Conscientização dos } \\
\text { funcionários }\end{array}$ & $17 / 03 / 2016$ & Panificação & $\begin{array}{l}\text { Comunicação } \\
\text { distorcida }\end{array}$ & Sócio gerente & Reunião com os funcionários. \\
\hline
\end{tabular}

Quadro 2-5W1H proposto para a panificação "Pão Quente"

Fonte: Elaborado pelos autores e colaboradores da empresa com base nos dados da pesquisa aplicada aos clientes e no Brainstorming. 
Após a elaboração do planejamento o próximo passo foi colocar em prática o que foi proposto, ou seja, executar de maneira que haja o bloqueio nas causas fundamentais. O resultado foi positivo, foi identificado melhora significativa nos rendimentos financeiros, mas o trabalho é cíclico e continuo, para então prevenir contra o reaparecimento do problema e recapitular todo o processo para trabalho futuro.

\section{CONSIDERAÇÕES FINAIS}

A pesquisa realizada proporcionou uma visão sistêmica da panificação em estudo. Foi possível conhecer os processos, analisar o nível de satisfação dos clientes, conhecer os problemas e suas soluções.

As reuniões foram dinâmicas e produtivas, os colaboradores demonstraram entendimento com a situação e se propuseram esforçar para conseguir atingir o objetivo.

Com a aplicação dos questionários aberto e fechado foi realizado os métodos estatísticos, nos quais junto com o brainstorming realizado facilitaram na elaboração do diagrama de causa e efeito, que demonstraram que as possíveis causas apuradas estavam vinculadas a Mão-de-obra, Produto, Gestores, Máquina, Matéria prima, Sistema, Método e Ambiente físico.

As ferramentas de qualidades escolhidas foram de fácil utilização, pois são flexíveis e adaptáveis a qualquer organização. Com elas foi possível mapear o processo e identificar as possíveis causas que estão causando o baixo rendimento financeiro da empresa.

As causas tratadas como prioridade são aquelas relacionadas a mão de obra, máquina e produtos que são: qualificação, motivação, absenteísmo, múltipla função, uniforme e aparência, quantidade de funcionário na área de venda, variedades dos produtos congelados de fabricação própria, falta de promoção, porção grande, climatização, planejamento da quantidade de produto produzido, falta de atenção, falta de cartão de crédito e fofoca, pois são os itens que estão interferindo na vida financeira da empresa.

Com isso, o plano de ação foi proposto e executado através do $5 \mathrm{~W} 1 \mathrm{H}$, resultando em melhorias no rendimento financeiro e na satisfação do cliente interno e externo, permitindo continuar competitiva no mercado.

\section{REFERENCIAS}

ASSOCIAÇÃO BRASILEIRA DAS INDÚSTRIAS DE PANIFICAÇÃO E CONFEITARIA; INSTITUTO TECNOLÓGICO DA PANIFICAÇÃO E CONFEITARIA; SERVIÇO BRASILEIRO DE APOIO ÀS MICRO E PEQUENAS EMPRESAS. Painel do mercado de panificação e confeitaria. 2011. Disponível em: <http://www.propan.com.br/encartetecnico/encartetecnico.html>. Acesso em: 30 out. 2013.

; PROGRAMA ALIMENTOS SEGUROS; confeitaria - da produção ao ponto de venda. 2010. Disponível em: $<$ http://www.abip.org.br/imagens/file/cartilhafinalizada\%20jun10-1.pdf $>$. Acesso em: 25 nov. 2013. 
AMORIM, M.B.; ROCHA, A.C.B. Redução de desperdícios em uma rede de suprimento de refeições coletivas por meio das ferramentas da engenharia de produção. In: SIMPÓSIO DE ENGENHARIA DE PRODUÇÃO, 19.,2012, Bauru. Anais... Bauru: SIMPEP, 2012.

CAMPOS, V.F. TQC - Controle da qualidade total (no estilo japonês). Nova Lima-MG: INDG Tecnologia e Serviços LTDA, 2004.

GARVIN, D.A. Gerenciando a qualidade: a visão estratégica e competitiva.

Tradução de João Ferreira Bezerra de Souza. Rio de Janeiro: Qualitymark, 2002.

HOSKEN, M.J. de C. Produzindo e montando sua qualidade. 2 ed. Disponível em: $<$ http://www.qualiblog.com.br/wp-content/uploads/2012/08/Produzindo_Montando_Qualidade.pdf>. Acesso em: 23 mar. 2014.

LEUSIN, M.E. et al. Metodologia MASP e ciclo PDCA na criação de um plano de ação: estudo de caso em uma empresa de varejo calçadista. In: ENCONTRO NACIONAL DE ENGENHARIA DE PRODUCAO, 33., 2013, Salvador. Anais... Salvador: ENEGEP, 2013.

MASIERO, G. Administração de empresas: teoria e funções com exercícios e casos. São Paulo: Saraiva, 2012.

MAZZOTTI, K., BROEGA, A. C., GOMES, L. V. N. The creativity exploration, through the use of brainstorming technique, adapted to the process of creation in fashion. In: INTERNATIONAL FASHION AND DESIGN CONGRESS, 1., 2012, Guimarães - Portugal. Proceedings... Guimarães Portugal: CIMODE, 2012.

PALADINI, E.P. Qualidade total na prática: implantação e avaliação de sistemas de qualidade total. São Paulo: Atlas, 1997.

PEREIRA, C.C.; et al. Processos da qualidade aplicado à produção de dutos de ar condicionado: um estudo sobre a efetividade na aplicação da qualidade como estratégia e eficácia operacional em uma fábrica x de Pernambuco. In: CONGRESSO VIRTUAL BRASILEIRO DE ADMINISTRAÇÃO, 8., 2011. Anais eletrônicos... CONVIBRA, 2011.

PIECHNICKI, A.S.; KOVALESKI, J.L. Roteiro de Aplicação do MASP: um Estudo de Caso na Indústria Madeireira. In: SIMPÓSIO DE EXCELÊNCIA EM GESTÃO E TECNOLOGIA, 8., 2011, Resende. Anais... Resende: SEGET, 2011.

PINTO, L.J.S; GOMES, J.S. Custos da Qualidade: um estudo de caso na panificadora Golden Vital. Revista de Informação Contábil, Recife, v.4, n.3, p. 57-76, jul./set. 2010.

PROGRAMA DE DESENVOLVIMENTO DA ALIMENTAÇÃO, CONFEITARIA E PANIFICAÇÃO. Informação PROPAN: tipos de panificação. Disponível em: $<$ http://www.propan.com.br/noticia.php?id=231\#.UxEdroWmXag>. Acesso em: 10 dez. 2013. $\overline{\text { dez. } 2013 .}$

Disponível em: <http://www.propan.com.br/institucional.php?idcat=12>. Acesso em: 10 2014.

Disponível em: $<$ http://www.propan.com.br/institucional.php?idcat=9>. Acesso em: 05 jan.

ROVERI, V. et al. MASP: método de análise e solução de problemas - aplicado à gestão das trilhas da Estação Ecológica Juréia Itatins/Núcleo Arpoador - Município de Peruíbe - SP. UNISANTA Law and Social Science, Santos, v.1, n.1, p. 30-34, jan./jun. 2012.

SILVA, A.D. et al. Analise da qualidade dos serviços de tecnologia da informação na gestão pública. In: SIMPÓSIO BRASILEIRO DE PESQUISA OPERACIONAL, 44., 2012, Rio de Janeiro. Anais... Rio de Janeiro: SBPO, 2012. 
SLACK, N. et al. Administração da produção. São Paulo: Atlas, 2009.

UNIVERSIDADE DE SÃO PAULO. Ferramentas de qualidade. Disponível em: $<$ http://portalses.saude.sc.gov.br/arquivos/sala_de_leitura/saude_e_cidadania/ed_03/pdf/07_01.pdf $>$. Acesso em: 23 de mar. 2014.

VILAÇA, L.L. et al. Melhoria do controle de peso de leite em pó enlatado em uma fábrica de laticínios. In: ENCONTRO NACIONAL DE ENGENHARIA DE PRODUCAO, 30., 2010, São Carlos. Anais... São Carlos: ENEGEP, 2010. 